\title{
The effects of acute tryptophan depletion on brain activation during cognition and emotional processing in healthy volunteers.
}

Citation for published version (APA):

Evers, E. A. T., Sambeth, A., Ramaekers, J. G., Riedel, W. J., \& van der Veen, F. M. (2010). The effects of acute tryptophan depletion on brain activation during cognition and emotional processing in healthy volunteers. Current Pharmaceutical Design, 16(18), 1998-2011. https://doi.org/10.2174/138161210791293060

Document status and date:

Published: 01/01/2010

DOI:

10.2174/138161210791293060

Document Version:

Publisher's PDF, also known as Version of record

\section{Document license:}

Taverne

Please check the document version of this publication:

- A submitted manuscript is the version of the article upon submission and before peer-review. There can be important differences between the submitted version and the official published version of record.

People interested in the research are advised to contact the author for the final version of the publication, or visit the DOI to the publisher's website.

- The final author version and the galley proof are versions of the publication after peer review.

- The final published version features the final layout of the paper including the volume, issue and page numbers.

Link to publication

\footnotetext{
General rights rights.

- You may freely distribute the URL identifying the publication in the public portal. please follow below link for the End User Agreement:

www.umlib.nl/taverne-license

Take down policy

If you believe that this document breaches copyright please contact us at:

repository@maastrichtuniversity.nl

providing details and we will investigate your claim.
}

Copyright and moral rights for the publications made accessible in the public portal are retained by the authors and/or other copyright owners and it is a condition of accessing publications that users recognise and abide by the legal requirements associated with these

- Users may download and print one copy of any publication from the public portal for the purpose of private study or research.

- You may not further distribute the material or use it for any profit-making activity or commercial gain

If the publication is distributed under the terms of Article $25 \mathrm{fa}$ of the Dutch Copyright Act, indicated by the "Taverne" license above, 
See discussions, stats, and author profiles for this publication at: https://www.researchgate.net/publication/43048975

\section{The Effects of Acute Tryptophan Depletion on Brain Activation During Cognition and Emotional Processing in Healthy Volunteers}

Article in Current Pharmaceutical Design · April 2010

DOI: 10.2174/138161210791293060 · Source: PubMed

CITATIONS

25

5 authors, including:

Anke Sambeth

Maastricht University

79 PUBLICATIONS 1,917 CITATIONS

SEE PROFILE

Wim J Riedel

Maastricht University

149 PUBLICATIONS 7,232 CITATIONS

SEE PROFILE

Some of the authors of this publication are also working on these related projects:

EU DRUID PROJECT View project

Role of acetylcholine and serotonin in novelty processing using an oddball paradigm View project
READS

1,352

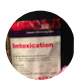

Johannes G Ramaekers

Maastricht University

310 PUBLICATIONS 8,882 CITATIONS

SEE PROFILE

Frederik M van der Veen

Erasmus University Rotterdam

104 PUBLICATIONS 1,921 CITATIONS

SEE PROFILE 


\title{
The Effects of Acute Tryptophan Depletion on Brain Activation During Cognition and Emotional Processing in Healthy Volunteers
}

\author{
E.A.T. Evers ${ }^{1}{ }^{*}$, A. Sambeth ${ }^{1}$, J.G. Ramaekers ${ }^{1}$, W.J. Riedel ${ }^{1}$ and F.M. van der Veen ${ }^{2}$ \\ ${ }^{I}$ Department of Neuropsychology and Psychopharmacology, Faculty of Psychology and Neuroscience, Maastricht University, \\ Maastricht, Netherlands ${ }^{2}$ Department of Psychiatry, Erasmus Medical Centre, Rotterdam, Netherlands
}

\begin{abstract}
Acute tryptophan depletion (ATD), a method to temporarily lower central serotonin levels, has been used to study the functioning of the serotonergic system. Relatively recent studies that examined the effects of ATD on brain activation associated with cognitive and emotional processing in healthy volunteers are reviewed. An overview of the findings in healthy volunteers is important for the interpretation of the effect of ATD on brain activation in patients with an affective disorder, such as major depression. These studies show that during response control and negative feedback processing ATD modulates the BOLD response in the inferior/orbitofrontal cortex, the anterior cingulate cortex and the dorsomedial prefrontal cortex. During emotional processing, it is consistently found that ATD modulates the BOLD response in the amygdala. These brain regions also show abnormal activation in depressed patients.

However, at the moment it remains unclear if the changes induced by ATD are related to decreased basal serotonin (5-HT) release or the result of other biochemical changes that are mediated by ATD. Future studies should implement methodological improvements, explore the possibilities of new promising imaging techniques and expand investigations into the effects of ATD on basal 5-HT release and other biochemical mechanisms that might be modulated by ATD.
\end{abstract}

Keywords: Serotonin, acute tryptophan depletion, cognition, emotion, fMRI, PET, EEG, MEG.

\section{INTRODUCTION}

In this review, studies that examined the effects of acute tryptophan depletion (ATD), a method to temporarily lower central serotonin (5-HT), on brain activation associated with cognitive and emotional processing are discussed. To better understand the effects of ATD in psychiatric patients and in volunteers who are more vulnerable to the effects of ATD, such as people with a genetic risk to develop major depression, it is important to first establish the effects of ATD in healthy volunteers. In this review, only studies that tested healthy volunteers without a history of affective disorder are included. Furthermore, functional Magnetic Resonance Imaging (MRI) studies that investigated the effects of ATD on brain correlates of cognitive and emotional processing started to appear in 2005; the first electroencephalogram (EEG) studies, sometimes combined with magnetoencephalogram (MEG), were first published only a few years earlier. In this review, these relatively recent articles will be discussed.

\subsection{The Serotonergic System}

5 -HT is a monoamine that is widely distributed in different organ systems. Ninety percent of the 5-HT in the human body is believed to exist in the mucous membranes and the gastrointestinal tract, $8 \%$ in blood platelets and $2 \%$ in the central nervous system [1]. In the latter, 5-HT synthesizing neurons are primarily found in the rostral and the caudal raphe nuclei. Axons from neurons in the raphe nucleus form a neurotransmitter system with ascending and descending pathways throughout the brain and the spinal cord (see Fig. 1). The rostral raphe nuclei consist of a dual serotonergic fiber system that originates from distinct cell groups in the brain: i.e. the dorsal and medial nuclei raphe. The former projects to areas such as striatum, prefrontal cortex (PFC), thalamus, amygdala, temporal lobe and cerebellum, whereas the latter projects to similar areas in the neocortex but also to the hippocampus. Fibers from the caudal raphe nuclei project to the cerebellum and the spinal cord [2]. The

*Address correspondence to this author at the Department of Neuropsychology and Psychopharmacology, Faculty of Psychology and Neuroscience, Maastricht University, Universiteitssingel 40, P.O. box 616, Maastricht, Netherlands; Tel: +31 (0)43-3884086; Fax: +31 (0)43-3884560; E-mail: lisbeth.evers@maastrichtuniversity.nl actions of 5-HT in these pathways are mediated by at least 7 receptor families that can also be further distinguished in several receptor subtypes [3]. Serotonin has been implicated in basic elements of behavioral and physiological control. Behavioral domains for which 5-HT is implicated include cognition, learning, sleep, social behavior, mood, impulsive emotion, appetite, anxiety and sexual behaviors. Physiological domains include thermoregulation, vasoconstriction, blood pressure and heart rate [1].

\subsection{Acute Tryptophan Depletion}

One method to examine the function of 5-HT neurotransmission in the brain is ATD. Since 5-HT cannot cross the blood-brainbarrier, its synthesis is dependent on its precursors, L-tryptophan (TRP) and 5-hydroxytryptophan (5-HTP). Namely, the amino acid TRP is first hydroxylated to 5-HTP, which is then synthesized to 5HT [4]. By ingesting a mixture containing large neutral amino acids but that is deficient in L-tryptophan, a reliable and reversible lowering of specifically TRP concentrations in the blood can be found [5-7]. Central depletion after ingestion of the drink can be achieved by the effects of 1) increased protein synthesis incorporating TRP in organs outside the central nervous system that reduces the available precursor in the plasma [5], 2) a decrease in the ratio of TRP to other lager neutral amino acids (LNAA) [8], and 3) competition between the large neutral amino acids that use the same amino acid carrier and TRP for transport into the central nervous system across the blood-brain-barrier [9].

In humans, ATD leads to a reduction of plasma TRP by $45-$ $90 \%$, which is reached around 4-7 hours after intake of the drink [6, 7]. Studies using rats have revealed that, next to a reduction in TRP ratios in the blood plasma, ATD also reduces TRP in several brain regions such as the hippocampus [10] and striatum [11]. Additionally, a $50 \%$ decline in 5-HT levels was found in the hippocampus, striatum, and cortex [11]. These findings extend to humans; ATD reduces cerebrospinal fluid TRP levels and decreases brain 5-HT synthesis $[12,13]$ demonstrating that ATD is a valid method for depleting 5-HT in the brain.

It must be noted that several variations in contents of amino acid mixtures have been used throughout the years. The mostly used drink is the so-called balanced amino acid mixture that is 


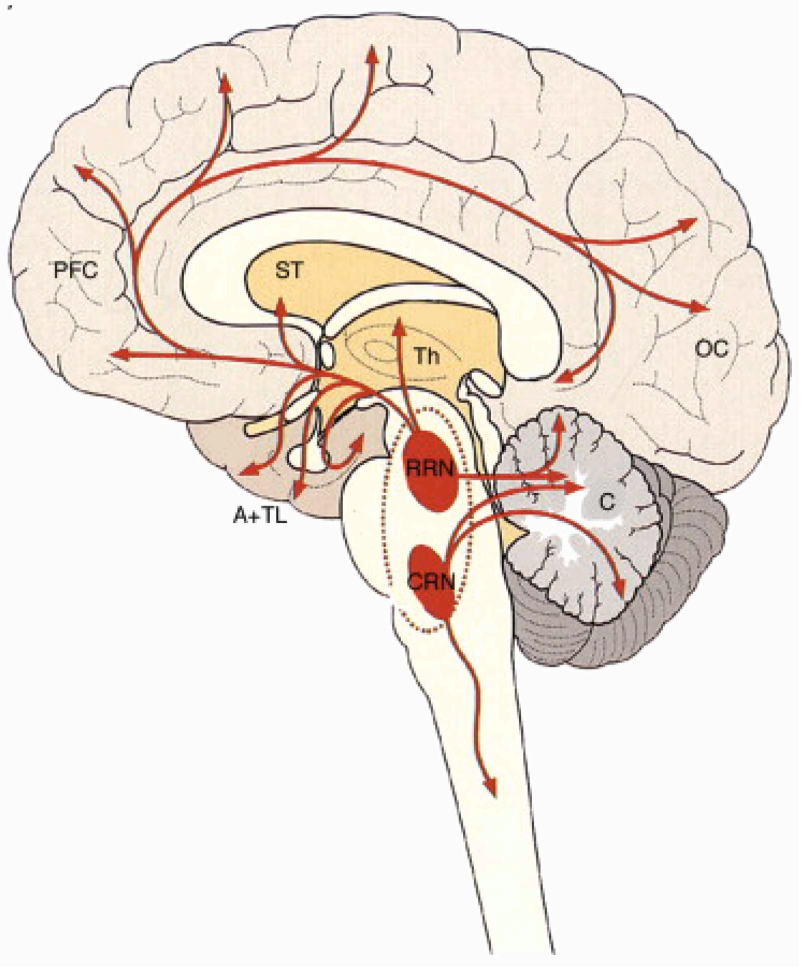

Fig. (1). Shown are $5 \mathrm{HT}$ projections from the caudal raphe nuclei (CRN) and one of the rostal raphe nuclei (RRN), i.e. the dorsal raphe nucleus. C, cerebellum; Th, thalamus; A, amygdala; TL, temporal lobe; ST, striatum; PFC, prefrontal cortex; OC, occipital cortex (adapted from Cools et al, 2007).

based on the one described by Young et al. [14] and contains $5.5 \mathrm{~g}$ L-alanine, $4.9 \mathrm{~g} \mathrm{~L}$-arginine, $2.7 \mathrm{~g}$ L-cysteine, $3.2 \mathrm{~g}$ L-lysine, $3.2 \mathrm{~L}$ histamine, $8 \mathrm{~g}$ L-isoleucine, $13.5 \mathrm{~g}$ L-leonine, $8.9 \mathrm{~g}$ L-lysine, $3.0 \mathrm{~g}$ methionine, $5.7 \mathrm{~g}$ L-phenylalanine, $12.2 \mathrm{~g}$ praline, $6.9 \mathrm{~g}$ L-serine, $6.9 \mathrm{~g}$ L-threonine, $6.9 \mathrm{~g}$ L-tyrosine, and $8.9 \mathrm{~L}$-valise. With this variant, the balanced drink contains the same amino acids to which $2.3 \mathrm{~g}$ TRP is added. At large two aspects have changed since this composition was reported: 1) the relative amount of TRP which was first $2.3 \%$ has increased and in many studies $4 \%$ TRP is added; 2) the total amount of amino acids has in many studies been reduced to $75 \mathrm{~g}$ using the same relative amounts of amino acids. In most imaging studies the $75 \mathrm{~g}$ or $100 \mathrm{~g}$ mixture was used, which reliably reduced plasma TRP.

\subsection{Acute Tryptophan Depletion and Cognition}

The most reliable effect of ATD on cognition is a modest impairment (5-10\% reduction of test scores) of the consolidation of declarative episodic memory for verbal information, while other types of memory, such as semantic memory and working memory, seem to be less or not affected by ATD (for review see [15]). In addition, previous studies suggest that ATD impairs cognitive flexibility. Cognitive flexibility refers to the ability to switch between behavioral strategies, when changes in the environment lead to alterations in the outcome of actions. Previous research suggests that 5-HT is involved in cognitive flexibility. Animal research showed that low 5-HT leads to inflexible behavior during reversal learning and response inhibition [16-19]. In humans, ATD impaired the ability to perform a reversal shift in an intra and extra dimensional shift task [20,21], impaired performance on a probabilistic reversal learning task [22] and impaired decision making [23] in healthy volunteers, although these effects were not consis- tently found. Furthermore, previous studies suggest that ATD might not affect [24, 25] or might improve focused attention [26-28], measured by a response interference paradigm.

5-HT plays an important role not only in cognition but also in emotion regulation (for a review see [29]). Previous studies have shown that ATD affects for example subjective emotional state [30] and the perception and interpretation of emotional stimuli [31] in healthy volunteers with a vulnerability of the serotonergic system, such as females and participants with a previous history of affective disorder treated with serotonergic medications [32].

What are the biological mechanisms that underlie the effects of ATD on cognition and emotional processing? In other words, in what brain regions is the neuronal activation during cognitive performance and emotional regulation modulated by ATD? Based on the serotonergic projections it can be hypothesized that ATD primarily modulates the activity in the terminal regions, such as the temporal lobe, including the amygdala and the hippocampus, and the prefrontal cortex (see Fig. 1).

In this article, we will answer this question by reviewing ATD neuroimaging studies that investigated the effect of ATD on brain activation during cognitive and emotional task performance. Most studies discussed in this review used functional Magnetic Resonance Imaging (fMRI) to measure brain activity. The outcome measure of fMRI is the Blood Oxygen Level Dependent (BOLD) response. The BOLD response reflects a regional increase in oxygen levels as a result of regional brain activity. The fMRI studies discussed in this review tested participants in a 1.5 or a 3 Tesla MRI scanner. Some studies discussed in this review, used EEG or a combination of EEG and MEG to assess brain activation. EEG is the recording of electrical activity along the scalp produced by the firing of neurons within the brain. MEG is an imaging technique that measures the magnetic fields produced by electrical activity in the brain.

Studies that examined the effects of ATD on the auditory evoked potentials [33-36], somatosensory evoked potential [37] or quantitative EEG during rest [38] will not be discussed. The studies discussed (see also Table 1) examined the effects of ATD on brain activation during response conflict (including response inhibition and response interference), feedback processing, memory and selective attention, and the processing of emotional stimuli. These studies used a within-subject double-blind crossover design, unless otherwise mentioned, and participants were tested from around 5 hours after consuming the amino acids.

\section{COGNITION}

In this section, neuroimaging ATD studies will be discussed that investigated the effects of ATD on the BOLD signal during response inhibition and response interference. Response control requires the ability to overcome interference by adequately inhibiting a strong but inappropriate response tendency.

\subsection{Response Control}

Rubia et al. [39] investigated the effects of ATD on the BOLD response during response inhibition. Volunteers performed a Go/NoGo task in which arrows were presented that pointed to the left, to the right or upward. Participants had to respond with the left or right response button according to the direction of the arrow (Go trials), or had to inhibit their response when the arrow pointed upward (NoGo trials). ATD reduced the number of left-right errors, but did not affect performance on NoGo trials. Furthermore, no effects of ATD on subjective mood were found. FMRI analysis showed that ATD decreased the BOLD response during response inhibition (NoGo compared to Go trials) in the right orbital and inferior PFC. ATD increased the BOLD response during response inhibition in the right middle temporal gyrus, the left superior/ middle and inferior temporal gyrus. The authors concluded that this data provides evidence for the hypothesis that 5-HT modulates 
Table 1. An Overview of the Neuroimaging Studies that Examined the Effects of ATD on Brain Activation During Cognition and Emotional Processing

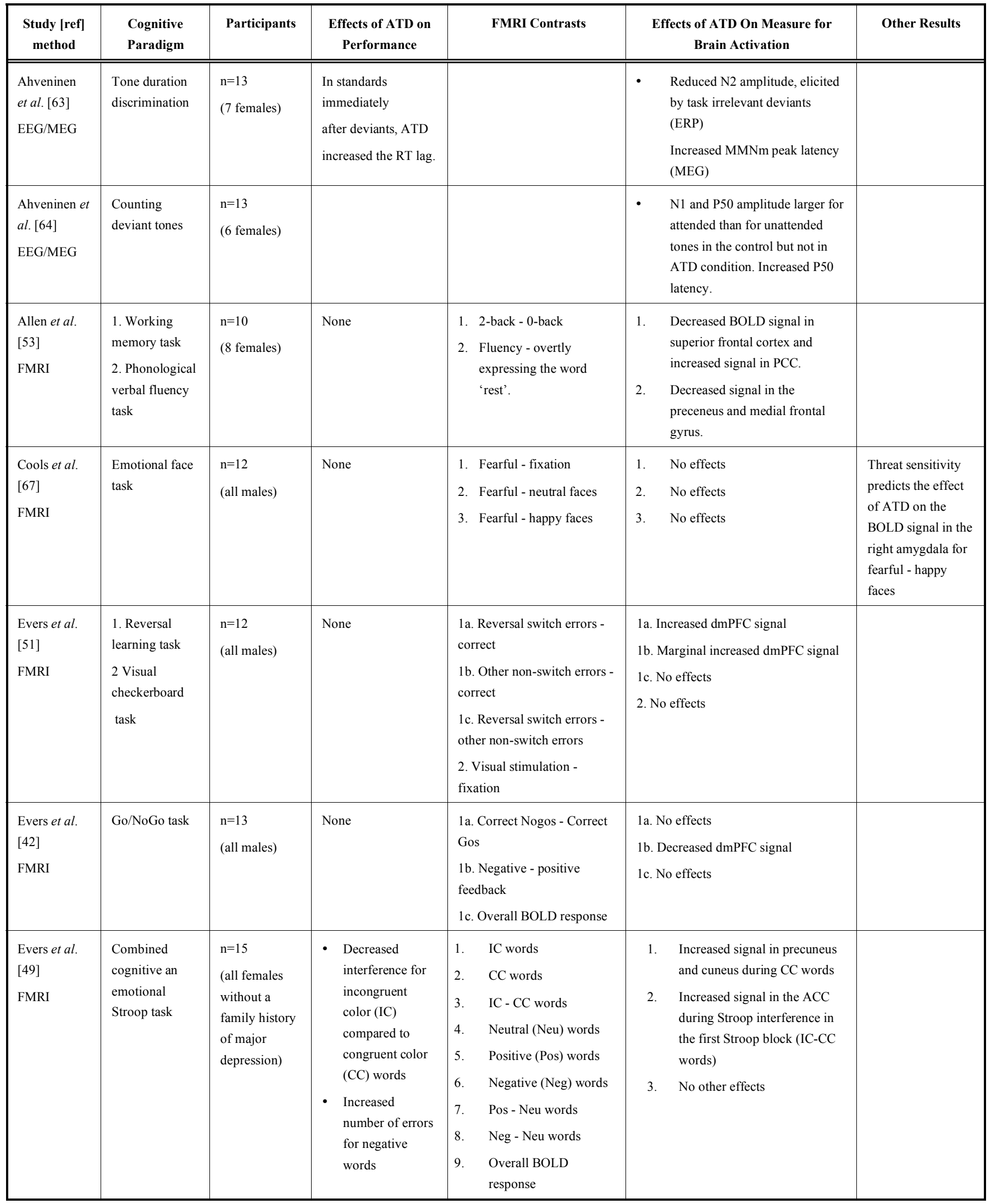


(Table 1) Contd....

\begin{tabular}{|c|c|c|c|c|c|c|}
\hline $\begin{array}{l}\text { Study [ref] } \\
\text { method }\end{array}$ & $\begin{array}{l}\text { Cognitive } \\
\text { Paradigm }\end{array}$ & Participants & $\begin{array}{l}\text { Effects of ATD on } \\
\text { Performance }\end{array}$ & FMRI Contrasts & $\begin{array}{c}\text { Effects of ATD On Measure for } \\
\text { Brain Activation }\end{array}$ & Other Results \\
\hline $\begin{array}{l}\text { Fusar-Poli } \\
\text { et al. }[70] \\
\text { FMRI }\end{array}$ & $\begin{array}{l}\text { Emotional face } \\
\text { task }\end{array}$ & $\begin{array}{l}\mathrm{n}=10 \\
\text { ( } 2 \text { females) }\end{array}$ & $\begin{array}{l}\text { ATD had no } \\
\text { significant effect } \\
\text { on gender } \\
\text { discrimination }\end{array}$ & $\begin{array}{ll}\text { 1. } & \text { Happy - neutral faces } \\
\text { 2. } & \text { Sad - neutral faces } \\
\text { 3. } & \text { Main effect of ATD } \\
\text { independent of } \\
\text { emotional valence }\end{array}$ & $\begin{array}{l}\text { 1. Decreased signal in PCC and } \\
\text { right lingual gyrus. Increased } \\
\text { signal in left precentral and } \\
\text { middle temporal gyrus } \\
\text { 2. Decreased signal in the left } \\
\text { lingual and right middle frontal } \\
\text { gyrus. Increased signal the left } \\
\text { inferior frontal gyrus and left } \\
\text { cerebellum. } \\
\text { 3. Decreased signal in the right } \\
\text { medial/IFC, the PCC, the } \\
\text { parietal and occipital cortex } \\
\text { bilaterally, right hippocampus, } \\
\text { claustrum and insula. Increased } \\
\text { signal in left IFG. }\end{array}$ & $\begin{array}{l}\text { ATD attenuated the } \\
\text { signal to emotional } \\
\text { (happy plus sad) } \\
\text { faces in the left } \\
\text { amygdala and } \\
\text { increased the signal } \\
\text { to emotional faces } \\
\text { in the right } \\
\text { amygdala. }\end{array}$ \\
\hline $\begin{array}{l}\text { Hughes et al. } \\
{[62]} \\
\text { EEG }\end{array}$ & Oddball task & $\begin{array}{l}\mathrm{n}=20 \\
\text { (all males) }\end{array}$ & & & $\begin{array}{l}\text { ATD not did change the } \\
\text { amplitude and latency of the } \\
\text { N1P2 and P300 to target tones, } \\
\text { omitted tones and frequent tones. }\end{array}$ & \\
\hline $\begin{array}{l}\text { Kähkönen } \\
\text { et al. [65] } \\
\text { EEG/MEG }\end{array}$ & Passive oddball & $\begin{array}{l}\mathrm{n}=14 \\
\text { ( } 7 \text { females) }\end{array}$ & & & $\begin{array}{l}\text { Increased amplitudes of } \\
\text { frequency and duration MMN, } \\
\text { and inter hemispheric latency } \\
\text { difference of frequency MMNm. } \\
\text { Increased P2m source signal and } \\
\text { changed latency at auditory } \\
\text { cortex. }\end{array}$ & \\
\hline $\begin{array}{l}\text { McAllister- } \\
\text { Williams et } \\
\text { al. [54] } \\
\text { EEG }\end{array}$ & $\begin{array}{l}\text { Episodic } \\
\text { memory task }\end{array}$ & $\begin{array}{l}\mathrm{n}=14 \\
\text { (all males) }\end{array}$ & $\begin{array}{l}\text { - No effect on } \\
\text { recognition } \\
\text { - Impaired source } \\
\text { memory } \\
\text { - } \begin{array}{l}\text { No effect ATD } \\
\text { on RTs }\end{array}\end{array}$ & & $\begin{array}{l}\text { Waveforms more positive after } \\
\text { ATD, with a greater effect at PZ } \\
\text { than Fz. } \\
\text { No effects on the magnitude of } \\
\text { the old/new effects (episodic } \\
\text { retrieval). }\end{array}$ & \\
\hline $\begin{array}{l}\text { Roiser et al. } \\
\text { [78] } \\
\text { FMRI }\end{array}$ & $\begin{array}{l}\text { Affective } \\
\text { Go/NoGo task }\end{array}$ & $\begin{array}{l}\mathrm{n}=20 \\
(13 \text { females })\end{array}$ & None & 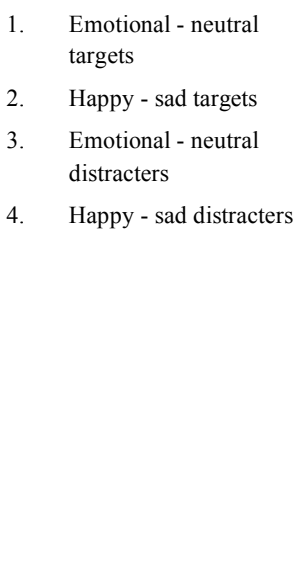 & $\begin{array}{l}\text { 1. Increased signal in left ventral } \\
\text { putamen, left thalamus and left } \\
\text { amygdala, right } \\
\text { parahippocampal gyrus, parietal } \\
\text { operculum, right anterior insula/ } \\
\text { putamen. Decreased signal in } \\
\text { right dorsolateral PFC. } \\
\text { 2. Decreased signal in right STG. } \\
\text { 3. Increased signal in right STG, } \\
\text { left PCC, left posterior } \\
\text { hippocampus, left dorsal } \\
\text { caudate, right inferior temporal } \\
\text { gyrus, right frontal operculum, } \\
\text { right vlPFC, right caudate. } \\
\text { Decreased signal in right dorsal } \\
\text { ACC. } \\
\text { Decreased signal in PCC. }\end{array}$ & $\begin{array}{l}\text { The STAI score } \\
\text { (anxiety) after ATD } \\
\text { correlates } \\
\text { positively with the } \\
\text { BOLD response in } \\
\text { the right caudate } \\
\text { for sad - happy } \\
\text { distracters (more } \\
\text { anxious greater } \\
\text { response) }\end{array}$ \\
\hline
\end{tabular}


(Table 1) Contd....

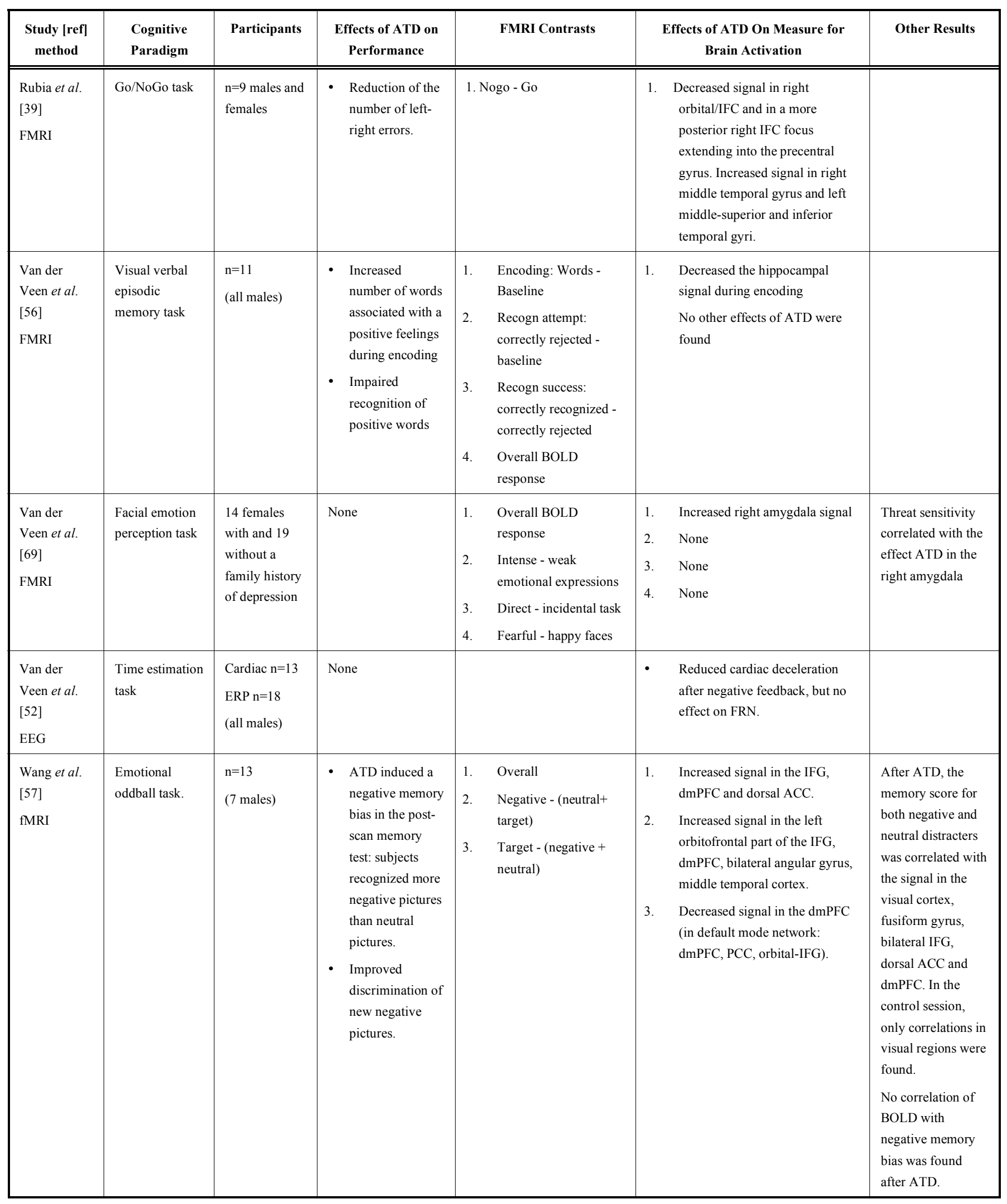


(Table 1) Contd....

\begin{tabular}{|c|c|c|c|c|c|c|c|}
\hline $\begin{array}{c}\text { Study [ref] } \\
\text { method }\end{array}$ & $\begin{array}{l}\text { Cognitive } \\
\text { Paradigm }\end{array}$ & Participants & $\begin{array}{l}\text { Effects of ATD on } \\
\text { Performance }\end{array}$ & & FMRI Contrasts & $\begin{array}{c}\text { Effects of ATD On Measure for } \\
\text { Brain Activation }\end{array}$ & Other Results \\
\hline $\begin{array}{l}\text { Williams et } \\
\text { al [71] } \\
\text { FMRI }\end{array}$ & $\begin{array}{l}\text { Emotional face } \\
\text { task }\end{array}$ & $\begin{array}{l}\mathrm{n}=8 \text { for effect } \\
\text { ATD on } \\
\text { BOLD }\end{array}$ & $\begin{array}{ll}\text { - } & \text { Overall, } \\
\text { decreased } \\
\text { response times. } \\
\text { - } & \text { Increased } \\
\text { number of errors } \\
\text { when processing } \\
\text { specifically } \\
\text { emotion shown } \\
\text { in profile. }\end{array}$ & $\begin{array}{l}1 . \\
2 .\end{array}$ & $\begin{array}{l}\text { Emotional judgment } \\
\text { condition - baseline. } \\
\text { Interactions }\end{array}$ & $\begin{array}{l}\text { 1. Decreased signal in left superior } \\
\text { temporal sulcus. } \\
\text { 2. } \\
\text { Decreased signal in medial PFC, } \\
\text { right temporal pole and OFC in } \\
\text { front-view. Increased signal for } \\
\text { faces in side-view in right } \\
\text { superior temporal sulcus and left } \\
\text { Broca. } \\
\text { Interaction ATD and emotion } \\
\text { type in amygdala: ATD } \\
\text { increased signal in right } \\
\text { amygdala to side-viewed happy } \\
\text { expressions; ATD increased } \\
\text { signal in left amygdala to front- } \\
\text { viewed fearful expressions }\end{array}$ & $\begin{array}{l}\text { For all conditions - } \\
\text { baseline } \\
\text { correlations with } \\
\text { plasma TRP were } \\
\text { found in } \\
\text { hippocampus, } \\
\text { intraparietal sulcus, } \\
\text { left insula, caudal } \\
\text { part of ACC, left } \\
\text { STG, bilateral } \\
\text { posterior temporo- } \\
\text { occipital junction. }\end{array}$ \\
\hline
\end{tabular}

Note. $\mathrm{ACC}=$ anterior cingulate cortex; $\mathrm{ATD}=$ acute tryptophan depletion; $\mathrm{dmPFC}=$ dorsomedial prefrontal cortex; IFC=inferior frontal cortex; $\mathrm{OFC}=\mathrm{orbitofrontal}$ cortex; $\mathrm{PCC}=$ posterior cingulate cortex; $\mathrm{PFC}=$ prefrontal cortex; $\mathrm{RT}=$ reaction time; $\mathrm{STG}=$ superior temporal gyrus; vlPFC=ventrolateral prefrontal cortex.

activity of the inferior frontal cortex during motor response inhibition [40, 41].

Also Evers et al. [42] examined the effects of ATD on the BOLD response during response inhibition. Volunteers performed a modified Go/NoGo task in which a stream of letters was presented. Each correct response, i.e. a response on a Go trial and no response on a No-Go trial, was followed by a green square (positive feedback), and each incorrect response was followed by a red square (negative feedback). In addition, a response that was too slow ( $>500 \mathrm{~ms}$ ) was also followed by negative feedback. ATD did not affect cognitive performance and no effects on mood were found. ATD did not change the overall BOLD response and did not change the BOLD response during response inhibition (correct NoGo trials compared to correct Go trials).

The study of Evers et al. [42] is in line with the majority of behavioral studies into the effect of ATD on response inhibition. These studies failed to find effects of ATD on motor response inhibition [e.g. 39, 43-47]. However, since fMRI is considered to be a more sensitive measure for changes in brain functioning than performance measures, the effect of ATD on brain functioning during response inhibition might have gone unnoticed in the behavioral studies. The different findings in the Rubia et al. [39] and the Evers et al. [42] study might be the result of differences in the response inhibition tasks that were used. The task used by Evers et al. [42] depended more on working memory and during the task feedback was provided whereas in the Rubia et al. [39] study the task was easier to perform and no feedback was given. Furthermore, in the Evers et al. [42] study only male volunteers were tested, while in the study of Rubia et al. [39] also females, who might be more vulnerable to the effects of ATD, were tested.

The effects of ATD on the BOLD response during response interference have been studied with the use of two different interference tasks, the Stroop and the Simon task. In a Stroop task, participants must override a predominant response tendency to read the meaning of the word and have to respond to the color of the ink. In a Simon task, participants must override a predominant response tendency to spatial information in order to respond to the direction indicated by small arrows.

Horacek et al. [48] studied the effects of ATD on the BOLD response during Stroop interference. In the MRI scanner, a modi- fied Stroop task was performed that contained blocks of congruent and incongruent trials. After the scan session, the standard three card version of the Stroop task was used to investigate the effect of ATD on Stroop performance. ATD did not change Stroop performance. FMRI data showed that ATD increased the BOLD response in the left inferior frontal gyrus and the right medial frontal gyrus during incongruent (compared to congruent) trials.

Evers et al. [49] examined the effects of ATD on the BOLD response during a combined cognitive and emotional Stroop task (for results on the emotional Stroop, see section 2.2). Healthy females without a family history of major depression participated in this fMRI study. With regard to performance, ATD reduced the interference for incongruent (compared to congruent) trials. FMRI analyses showed that ATD did not change the overall BOLD response. Furthermore, it was shown that ATD increased the BOLD response in the left precuneus and cuneus during congruent color words, and increased the BOLD response in the anterior cingulate cortex in the first Stroop block during incongruent color (compared to congruent color) words.

Lamar et al. [50] studied the effects of ATD on the BOLD response during a Simon task in older adults. In this task arrows were presented that were either pointing to the left or the right while being projected to the same side of where they pointed (e.g. pointing to the right and being presented on the right side of the screen; congruent trials, $76 \%$ ) or the opposite side of where they pointed (e.g. pointing to the right and being presented on the left side of the screen; incongruent trials, 12\%). Additional arrows pointed at a slide angle (congruent trials; $12 \%$ ). ATD decreased the mean state aggression scores but did not change performance on the Simon task. FMRI analyses showed that ATD decreased the BOLD response in the right anterior cingulate cortex, the left inferior frontal gyrus and the right striatum, particularly the caudate and putamen, and increased the BOLD response in the cerebellum bilaterally, the left inferior parietal lobule regions, the peristriate regions (cuneus and precuneus) bilaterally, the right lingual gyrus, the fusiform and parahippocampal gyrus bilaterally, during incongruent color (compared to congruent color) words.

These studies show that a number of regions are modulated by ATD. The results suggest that ATD increases the BOLD response in the PFC during incongruent trials in the Stroop task, and 
increases the BOLD response in more posterior regions during incongruent trials in Simons task.

\subsection{Feedback Processing}

Receiving negative and positive feedback is important for behavioral rule learning such as in a reversal-learning task (reinforcement learning) and for performance monitoring. Previous studies have shown that the 5-HT system is implicated in punishment sensitivity (for review see [29]).

Evers et al. [51] investigated the effects of ATD on the BOLD response during a reversal-learning task. In this task, two stimuli were presented simultaneously and the participants had to respond by button press to the stimulus that was rewarded most of the time. When the participants had learned the stimulus-response rule, the rule was reversed, such that now the other stimulus was correct most of the time. After each trial, positive or negative feedback was given. Although ATD tended to increase the overall reaction time, no significant effect of ATD on performance was found. ATD did not change the overall BOLD response during the reversal learning task and did not change the task-related BOLD response during a visual checkerboard task (control task). Event-related analyses showed that ATD increased the BOLD response in the right dorsomedial PFC during trials in which negative feedback was followed by a behavioral switch (compared to baseline correct trials). Because the BOLD response was not changed after a behavioral switch and was only marginally increased after negative feedback, the authors argued that this suggests that ATD increases the BOLD response in the dorsomedial PFC during negative feedback.

Evers et al. [42] examined the effects of ATD on negative feedback in a Go/NoGo task (for task description see above). It was found that ATD decreased the BOLD response in de dorsomedial PFC during the receipt of negative feedback (compared to positive feedback).

Van der Veen et al. [52] investigated the effects of ATD on the feedback-related negativity. The feedback-related negativity is an event-related brain potential (ERP) component that is found at central electrodes $(\mathrm{Cz})$ about $300 \mathrm{~ms}$ after the presentation of feedback. In this study, twenty healthy volunteers performed a time-estimation task, in which they estimated the duration of one second. After each response, feedback was given on how well they had estimated the duration. ATD did not change performance and did not change the amplitude of the ERPs related to positive and negative feedback. Although not a measure of brain functioning, ATD attenuated the phasic cardiac slowing to negative feedback.

In sum, the two BOLD fMRI studies $[42,51]$ suggest that ATD modulates the BOLD response in the dorsomedial PFC during negative feedback processing. An EEG study [52] did not show effects of ATD on electrical brain activity during the receipt of positive and negative feedback, but did show that ATD attenuated the cardiac slowing related to negative feedback.

\subsection{Verbal Fluency}

Allen et al. [53] examined the effects of ATD on the BOLD response during a working memory (see section 3 'memory' for results) and a phonological verbal fluency task. The verbal fluency task consisted of blocks in which the participants were asked to generate a word that starts with a given letter (task condition), or were asked to overtly articulate the word 'REST' (control condition). ATD decreased the BOLD response in the left medial frontal gyrus and in the precuneus during word generation (compared to word repetition). No ATD effects were found on mood and performance.

\subsection{Memory}

As noted above, one of the robust findings in ATD research has been that ATD impairs episodic memory consolidation rather than other types of memory (for review see [15]. Several studies assessed the neuronal correlates of these findings.

McAllister-Williams and colleagues [54] examined the effects of ATD on brain activity during a verbal learning task. Participants were instructed to judge whether a spoken word was presented for the first time, or whether it was a repetition. This task assessed recognition of episodic memory. Furthermore, source memory was assessed by judging whether the word was spoken by a male or female voice. Only source memory was impaired after ATD, but not recognition per se [54]. Brain activity, as measured with late components of the event-related potential, was increased after ATD in posterior electrode locations in response to the processing of both new and repeated items. McAllister-Williams et al. [54] suggested that ATD may generally affect brain function, but is not related to specific aspects of retrieval. One interesting feature of these results is the increase in brain activity related to memory processes after ATD. Generally, a large amplitude on parietal electrodes is attributed to good memory performance (e.g. [55]).

Two recent studies investigated the effects of ATD on the BOLD response during memory $[56,57]$. In the study by Van der Veen et al. [56], during encoding participants were presented with words that should be rated as giving a positive or a negative feeling. The participants gave a new/old judgment for the words in the recognition phase. More words were associated with a positive feeling after ATD than after the balanced drink in the encoding task. During recognition, however, ATD impaired performance for the positively associated words. The BOLD response in the hippocampus was decreased after ATD during encoding, whereas no changes were seen in BOLD response during the recognition phase. This suggests that ATD may affect both memory encoding and consolidation, because the latter process already starts during the encoding task (see also $[27,58]$ ).

Wang et al. [57] examined the effects of ATD on the BOLD response during an emotional oddball task. In this task, participants had to respond to target pictures, but not to negative and neutral pictures that were presented as distracters. In a later recognition task, ATD improved discrimination for negative stimuli. This was accompanied by increased BOLD activity in the left orbital part of the IFG, dorsomedial PFC, and bilateral angular gyrus and middletemporal cortex areas. However, several procedural flaws are present in this study such as an open-labeled design and the use of water as control drink instead of a balanced amino acid mixture, which makes the interpretation of the results complex. Therefore, these results should be interpreted with caution.

A last study that assessed memory effects of ATD was related to working memory [53]. Even though this type of memory has usually been related to dopamine function in frontal cortical areas [59], recently it was suggested that also 5-HT might play a role. Participants performed a 2-back task, in which they were instructed to indicate if the currently presented letter was the same as that presented two trials before. ATD did not affect the behavioral performance in this task as compared to the balanced drink, but the BOLD response was significantly decreased in the right superior/ medial frontal gyrus. Furthermore, greater activity was found in the posterior cingulate gyrus, which was due to an attenuation of the response to the control task, a 0-back task.

In sum, imaging studies suggest that the episodic memory impairments are due to reduced activation of the hippocampus, even though the late positive component in the EEG suggested an improvement. Furthermore, working memory is somewhat impaired after ATD, which is associated with reduced BOLD activity in frontal areas.

\subsection{Selective Attention}

Attention is mediated by various regions in the brain including the PFC, the anterior cingulate cortex, and posterior parietal 
cortices (e.g. [60, 61]). Given the fact that ATD has previously shown to improve selective attention processes [26, 27], and since the PFC and anterior cingulate regions were affected by ATD in the working memory study by Allen and colleagues [53], it is possible that the attention effects are mediated by these brain areas. However, to our knowledge no fMRI studies have yet been performed that are entirely dedicated to selective attention processes. Only a few EEG/MEG studies examined whether ATD can modulate brain activity related to attention.

Three studies used an active oddball task, in which frequent non-target tones were interspersed with infrequent target tones [6264]. Hughes and co-workers [62] showed that none of the eventrelated potential components related to attention, namely the N1/P2 and the P300 in response to target tones, were affected by the ATD procedure. Also reaction times did not differ between the ATD and control condition. Unfortunately, they did not specify the task instructions.

In the first study by Ahveninen and colleagues [63], volunteers were presented with tones that did not only differ in stimulus frequency, but also duration. They were instructed to distinguish duration of the tones, but to ignore the frequency changes. ATD reduced the amplitude of the attention-related $\mathrm{N} 2$ component. In another study, Ahveninen et al. [64] combined an oddball task with a dichotic listening task. Participants were instructed to attend target tones in one of both ears and to silently count the number of target stimuli. ATD reduced the amplitude enhancement of P50 and $\mathrm{N} 1$ to the selectively attended tones [64].

One of the EEG/MEG studies on attention-related processes used a passive oddball [65]. In such a task, the target tone elicits a mismatch negativity component; a component occurring around 100-200 ms after stimulus presentation and that is related to preattentive sensory memory processes (see [66] for a review). Volunteers were presented with tones differing in frequency and duration while watching a silent video for distraction. ATD increased the amplitude of the mismatch negativity.

To summarize, early cortical brain responses were affected in three out of four attention-related experiments. However, the results here are counterintuitive to the previous behavioral studies. Where attention improvements were previously found [27], the EEG/MEG studies mainly showed reductions in attention-related components, normally indicating decreased attention. ATD, thus, does play a role in early perceptual processing, but future research should focus on the interplay between behavioral responses and brain activity during attention.

\section{EMOTIONAL PROCESSING}

In order to express appropriate emotions in interactions with other people it is necessary that emotions in other people are properly perceived and processed. An important cue in this respect is the emotional face expression. In this section studies using ATD and fMRI during processing of emotional faces and words will be reviewed.

\subsection{Emotional Faces}

Emotion is important for appropriate behavior in social contexts and is, among other things, dependent on the proper perception and further processing of emotion in other people. The most informative cue in this respect is the emotional face expression.

Cools et al. [67] examined the effects of ATD during the perception of emotional face expressions with an implicit emotional processing task. Volunteers were asked to categorize the gender of neutral, fearful and happy faces. The main finding of their study was that the effect of ATD on the BOLD response in the right amygdala in the contrast fearful minus happy faces correlated positively with a measure of threat sensitivity as determined with the BIS/BAS scales of Carver \& White [68]. Higher threat sensitivity scores were associated with a larger effect of ATD on the fear related amygdala response. Cools et al. [67] could not find any other effects of ATD on the BOLD signal and, furthermore, found that ATD did not affect performance scores and subjective mood ratings.

Van der Veen et al. [69] investigated the effects of ATD on the BOLD response during face processing with an explicit task or an implicit emotional processing task. Females with and without a family history of depression participated. This section will only focus on the results regarding the females without a family history of depression. The participants performed either a direct emotion categorization task or an indirect gender categorization task. In the gender task the participants had to select which of the two presented pictures that was most male and in the emotion task participants had to select the picture which was most emotional. Morphed faces were used, in which a male or female neutral face was morphed with a male or female emotional face. This resulted in two groups of faces with a weak emotional expression (10 or $30 \%)$ and two groups of faces with a strong emotional expression (70 or $90 \%)$. In this study fearful, disgusted, sad and happy faces were used, and most analyses focused on the difference between fearful and happy expressions. The main finding was that ATD enhanced the overall amygdala response to faces. Moreover, it was found that this effect was stronger in the contrast between fearful and happy faces. Additionally, van der Veen et al. [69] replicated the findings of Cools et al. [67] in showing that the right amygdala response to fearful faces correlated with threat sensitivity as measured with the BIS/BAS scales.

Fusar-Poli et al. [70] examined the effect of ATD on face processing with an implicit emotional processing task in ten volunteers. Fusar-Poli et al. [70] used happy, neutral and sad pictures. The main finding of this study was that independent of type of emotion, ATD attenuated the BOLD response in several cortical and subcortical areas and increased the BOLD response in the left inferior frontal gyrus. Furthermore, the authors reported a differential response in the right and left amygdala, i.e., the right showed an increased BOLD response after ATD, whereas the BOLD response in the left amygdala was attenuated after ATD. This effect was independent of type of expressed emotion. Finally, ATD did not affect performance and subjectively rated mood.

Williams et al. [71] studied the effects of ATD on the BOLD response during face processing with an explicit emotional processing task. In the used task the participants viewed front-viewed or side-viewed faces, expressing a strong (100\% emotional), weak (50\% emotional $/ 50 \%$ neutral) emotion or no emotion (neutral) and were asked to decide whether the expression was neutral or emotional. ATD reduced activity independent of face view in the left superior temporal sulcus and the anterior cingulate gyrus. Modulatory effects of ATD were also found in other brain areas, but these were dependent on whether faces were front-viewed or side-viewed. Activity in the amygdala depended on both view type and emotion, i.e., right amygdala showed a stronger increase following ATD for viewing side-viewed happy faces, whereas the left amygdala showed a stronger increase following ATD for frontviewed fearful faces. ATD had an overall effect on performance leading to faster, but less accurate responses.

A common finding in all four studies is that ATD affects the BOLD response to emotional faces in the amygdala. All studies reported some kind of increased BOLD response in the amygdala in response to viewing negative face expressions. In three out of four studies the right amygdala response was more sensitive and the effect was also present independent of individual personality characteristics. Two studies reported a relation with subjectively reported threat sensitivity scores and the other two studies did not measure this trait. The sensitivity of the amygdala to ATD in the context of emotion processing fits with other lines of research that have repeatedly shown that the amygdala plays a central role in 
emotion [72], that the amygdala is sensitive to genetically determined differences in the serotonin metabolism (e.g. [73]) and that amygdala function is disturbed in psychiatric illnesses characterized by large changes in emotion regulation such as major depression [74]. On the other hand, effects on other brain areas appeared to be very variable and are possibly dependent on the different task paradigms. It should be noted that the impact of most studies is limited by the relatively small number of participants that is included and that comparability is hampered by gender differences of the tested volunteers. On the other hand these weaknesses further stress the importance of the consistent effect of ATD on the BOLD response in the amygdala.

The overall finding that ATD increases the BOLD response in the amygdala is in line with fMRI studies that have shown that selective serotonergic reuptake inhibitors (SSRIs) reduced the amygdala response in emotion induction tasks [75-77]. This effect has been found in depressed patients who were treated for a couple of weeks $[75,76]$ or only pre-treated with a single dose [77]. So, it can be concluded that the amygdala is very sensitive to 5 -HT interventions and that the ATD technique is powerful enough to highlight this sensitivity.

\subsection{Emotional Words}

Roiser et al. [78] investigated the effects of ATD on the BOLD response during emotional information processing with an affective Go/NoGo test. Volunteers completed a slightly modified ATD experiment. In this task words of different emotional valences (positive, negative or neutral) were presented, participants had to respond to each word of a particular valence and not respond to each word of the other valence, and words in all categories could either be target or distracter. The main finding of the study was that ATD increased BOLD responses in contrasts comparing emotional and neutral distracters or targets in a number of cortical and subcortical areas. For targets increases were found in left putamen, left thalamus, left amygdala, right parahippocampal gyrus, bilateral parietal operculum, and right anterior insula. For distracters increases were found in right superior temporal gyrus, left hippocampus, bilateral caudate nucleus, right inferior temporal gyrus and right ventrolateral PFC. Roiser et al. [78] also found an interesting relation with subjective mood, i.e., participants who reported more anxiousness following ATD also showed an increased BOLD response in the caudate in a contrast comparing negative and positive distracters. ATD only slightly affected performance in this task, leading to a somewhat stronger bias towards emotional stimuli (independent of valence) in the accuracy data.

Evers et al. [49] studied the effects of ATD on emotional information processing in an fMRI study in which participants performed a mixed emotional and cognitive Stroop task. Emotional (positive/negative), neutral and color (congruent/incongruent) words were presented in four different colors and participants had to respond to the color of the words and ignore the meaning of the word. Here, we will focus on the results regarding the emotional part of the Stroop task. The main finding was that ATD did not affect the BOLD response in any of the tested contrasts. Moreover, the relation with subjectively reported mood was also absent. The only effect of ATD in the emotional Stroop task in this study was a significant increase in the percentage of errors on negative words.

The results of the two reviewed studies are not very comparable which is possibly related to the large task differences (Stroop vs. Go/No-Go) and different experimental designs (standard amino acids mixture in tap water vs. low quantity in capsules). The Evers et al. [49] study could not find any effect of ATD on the BOLD response in any region and any contrast, whereas the Roiser et al. [78] study reported effects in a large number of regions and in a number of different contrasts. Besides the effect of ATD on many areas involved in emotion processing, Roiser et al. [78] also reported an increase the BOLD response in the amygdala which is in line with the studies reviewed in the previous section which consistently showed a strong sensitivity of this brain region to ATD.

\section{DISCUSSION}

ATD neuroimaging studies showed that the BOLD response in some brain regions is changed more frequently than in other regions. The BOLD response in the inferior frontal cortex, the dorsomedial PFC, the anterior cingulate cortex, the orbitofrontal cortex and the amygdala is often found to be modulated by ATD. More specifically, ATD neuroimaging studies showed that during response control and negative feedback processing ATD modulates the BOLD response in the inferior/orbitofrontal, the anterior cingulate cortex and the dorsomedial PFC. The effects of ATD on brain activation during memory and selective attention tasks are less clear. Only few studies into the effects of ATD on memoryrelated brain activation have been carried out, and the ones that were carried out studied different memory processes. No ATD neuroimaging study was entirely dedicated to selective attention. During emotional processing, it was shown that ATD modulates the BOLD response in the amygdala.

Major depression has been related to disturbances of the 5-HT system, such as lower levels of central 5-HT [79]. It has been shown that ATD leads to a relapse in $50-60 \%$ of selective serotonin reuptake inhibitor (SSRI) treated remitted depressed patients (for review see [32]). Furthermore, ATD induced depressed mood in healthy people who are more vulnerable to develop major depression, such as people with the s/s genotype for the 5-HT transport (SERT) and people with a positive family history of affective disorder [32, 80-85]. In line with cognitive disturbances found in depressed patients, ATD impaired memory consolidation [15] and cognitive flexibility $[20,21]$ in healthy volunteers. These findings suggest that ATD might induce a state in healthy volunteers that resembles major depression, although in a much milder form. Interestingly, the regions that have found to be modulated by ATD, such as the dorsomedial PFC, the orbitofrontal cortex, and the amygdala, are found to be abnormally activated in depressed patients. Previous studies showed reduced glucose metabolism and reduced gray matter in these regions in depressed patients (for review see [86]).

\subsection{The Effect of ATD on the 5-HT System}

To clarify the influence of ATD on the functioning of the 5-HT system, previous studies have investigated the effect of ATD on 5HT synthesis, the 5-HT transporter and different 5-HT receptor types. The results of a positron emission tomography (PET) study indicate that ATD decreases the synthesis of 5-HT throughout much of the cerebral cortex of healthy volunteers [12]. In addition, it was shown that women had a lower baseline 5-HT synthesis than men and that ATD decreased 5-HT synthesis more in women than in men. In response to criticisms of the used methods, the authors improved the methods and replicated the finding that in women the 5-HT synthesis is lower than in men [87]. However, the effects of ATD on 5-HT synthesis were not reexamined.

Animal research suggests that the location of the 5-HT transporter (SERT) is affected by the levels of synaptic, i.e. extracellular 5 -HT $[88,89]$. Decreased synaptic levels of 5-HT are thought to translocate the SERT away from the plasma membrane resulting in decreased SERT density in the plasma membrane and therefore decreased binding of a SERT tracer. Talbot et al. [90] therefore put forward the hypothesis that changes in extracellular 5-HT will change the binding potential of a radiotracer to image the SERT. However, they failed to find effects of ATD on the binding potential of the SERT tracer 11C-DASB, and concluded that the SERT tracer binding is not sensitive to detect decreased levels of synaptic 5-HT associated with ATD. The alternative explanation that ATD does not alter synaptic 5-HT is considered to be unlikely since animal studies showed that brain 5-HT is depleted after ATD. 
Praschak-Rieder et al. [91] examined the effect of ATD on the affinity and density of SERT, since changes in affinity and density of the SERT could be a compensatory mechanism to maintain sufficient extracellular levels of 5-HT after ATD. The results showed no effects of ATD on the regional SERT tracer (11CDASB) binding potential, which suggests that ATD does not alter SERT affinity and density.

Both Udo de Haes et al. [92] and Rainer et al. [93] investigated the effect of ATD on the binding potential of a tracer for 5-HT1A receptors in healthy volunteers. Both studies failed to find consistent effects of ATD on the binding of the 5-HT1A tracer. Yatham et al. [94] examined the amount of 5-HT2 receptor binding of a radioactive tracer after ATD compared to placebo in healthy volunteers. They showed decreased 5-HT2 receptor binding in the left fusiform gyrus, the left insula, the left superior temporal gyrus, and the left superior frontal gyrus. This decrease in binding potential, which is indicative for increased 5-HT levels, was not expected. The authors argued that the data might indicate that decreased levels of 5-HT trigger an adaptive response, such as reduced density of the number of 5-HT2 receptors, to protect against depressive symptoms.

Chair et al. [95] studied the effects of ATD on the 5-HT1A and 5-HT2A receptor binding (in-vitro) in the rat brain. They showed that ATD significantly reduced somatodendritic 5-HT1A binding in the dorsal raphe by $14 \%$. However, no changes in postsynaptic 5HT1A reduction were found in the cortex and the hippocampus. In line with Yatham et al. [94], Chair et al. [95] showed that 5-HT2A binding in the cortex was reduced after ATD. However this reduction was not significant, which might be related to the greater variability in in-vitro radioligand binding compared to in-vivo PET.

In sum, these studies suggest that ATD decreases the synthesis of 5-HT in the brain, does not affect the density or affinity of the SERT, decreases the density of the 5-HT2 receptor, and might have an effect on the somatodendritic 5-HT1A receptors.

\subsection{The Effect of ATD Explained by the Effect on Other Neuro- transmitter Systems}

The 5-HT, norepinephrine (NE), dopamine (DA), and acetylcholine (ACh) neurotransmitter systems largely overlap in terms of their being widespread in their anatomical organization. Not only are the origination brain stem nuclei interconnected, these systems also have overlapping terminal fields and innervation patterns [2]. Briand et al. [96] stressed the importance to focus on the regulatory and functional interactions between these systems, rather than studying these neurotransmitter systems in isolation.

5 -HT is known to have inhibitory influences on NE, ACh, and DA turnover [97]. In particular, an increased relative influence of NE transmission brought about by decreased 5-HT turnover might explain the positive effects of ATD on focused attention. Importantly, it must be noted that if in an experiment, independent variable $\mathrm{X}$ is manipulated leading to a change in dependent variable $Y$, experimental methodology only permits conclusions attributing the change in $\mathrm{Y}$ to varying levels of $\mathrm{X}$. Suppose that the manipulation of $X$ induces changes in $Y$, but these are known to be actually accomplished by $Z$, in such a way that it would have been more appropriate to manipulate $\mathrm{Z}$ rather than $\mathrm{X}$. One should attempt to either manipulate or control $\mathrm{Z}$ or measure its known indicator(s). According to experimental methodology, one may only speculate but not conclude about the potential mediating influence of $\mathrm{Z}$. In the example above, $X$ refers to $5-\mathrm{HT}, \mathrm{Y}$ to cognitive performance or neuroimaging variables, and $\mathrm{Z}$ refers primarily to NE. We would like to stress that drawing conclusions about $Z$ on the basis of experiments in which $\mathrm{X}$ is systematically varied and changes in $\mathrm{Y}$ are measured, are in general not permitted. So in the above example one may only speculate about the role of NE in the effects of ATD on focused attention.
Previous studies suggest that ATD does not affect DA levels. It was shown that ATD did not change cerebrospinal fluid levels of tyrosine [98], plasma, cerebrospinal fluid and brain levels of DA metabolites [11, 26, 98], the concentration of DA in the brain [99], and the DA efflux in the medial PFC [100]. Furthermore, ATD did not change the concentration of NE levels in the brain [99]. To the best of our knowledge no study so far has investigated the effect of ATD on ACh release. Interestingly, Lieben et al. [101] showed that metrifonate, an acetylcholinesterase inhibitor, which increases ACh in the synapse, reversed the memory deficits that were induced by TRP depletion in rats. These findings suggest that the effects of ATD might be due to specific effects on the 5-HT system.

\subsection{Interpretation of the Results of the ATD Neuroimaging Studies}

A number of factors make the interpretation of the effect of ATD on the BOLD response not straightforward.

\section{Confounding Factors}

A number of known confounding factors, such as personality and genetic 5-HT vulnerability, are not consistently taken into account in these ATD neuroimaging studies. It has been shown that personality characteristics interact with the effect of ATD. For example, self reported threat sensitivity correlated positively with the ATD-induced increase in BOLD response in the amygdala [67] and impulsivity correlated negatively with ATD-induced rewardrelated speeding on a reaction time task [44]. In addition, participants with an increased vulnerability of the 5-HT system are more sensitive for the effects of ATD. In participants with two small alleles of the 5-HT transporter linked polymorphic region, but not in participants with two long alleles, ATD decreased motivationally speeded action [102], and a stronger bias toward choosing the certain option in a decision making task was found in participants with two small alleles [103]. Furthermore, ATD impaired immediate and delayed recall on an episodic verbal memory tasks more in females than in males [104]. To improve the interpretation of the findings of ATD studies, factors that are known to modulate the effect of ATD should be controlled for.

\section{Pharmacological Neuroimaging}

Pharmacological functional Magnetic Resonance Imaging (phfMRI) is a method that enables the measurement of changes in brain activation evoked by drug treatment. BOLD fMRI, the method mostly used, does not measure neural activity directly, but relies on a cascade of physiological events linking neural activity to the generation of the MRI signal. Most ph-fMRI studies performed so far have interpreted changes in BOLD signal as changes in "brain activation", ignoring the potential confounds that can arise through drug-induced modulation on the events downstream of the neural activity [105]. Since drug treatment can change the neurovascular response, a drug has the potential to change the BOLD response without changing neural activity. Therefore methodological improvements are needed to interpret changes in BOLD signal.

\section{5-HT Mediated Instead of 5-HT Induced}

There is still no direct evidence that ATD alters brain 5-HT release, i.e. that ATD actually alters the functional activity of the 5HT neurons [106]. It has been shown that ATD reduces plasma TRP, brain TRP, 5-HT and 5-HIAA in rats (e.g. [5]), and reduces plasma TRP, plasma ratio TRP/LNAA, TRP and 5-hydroxyindoleaceticacid (5-HIAA; 5-HT metabolite) levels in cerebrospinal fluid (e.g. [107]), and synthesis of brain 5-HT in humans [12]. However, these measures are only estimates for the 5-HT neuronal activity. It is possible that in the absence of new 5-HT synthesis, 5HT function can be largely maintained from 5-HT being recycled from the synapse into the presynaptic cell. It has been shown that without an initial increase in 5-HT concentration, basal 5-HT release in the medial PFC of the rat appeared not to be affected by 
ATD [100]. Moreover, decreased levels in whole brain 5-HT and 5HIAA levels in the cat did not parallel changes in functional activity of 5-HT containing raphe nucleus cells [108]. These findings suggest that other mechanisms might be responsible for the effects of ATD on behavior, mood and the underlying brain activation [106].

Furthermore, it could be argued that the ATD neuroimaging studies should have tested the participants at a later moment. Namely, at the moment that not only the levels of brain TRP and 5HT synthesis have decreased, but also the still available brain 5-HT is released and metabolized. Brain 5-HT turnover could be accelerated by experimental manipulations that lead to increased 5HT release, such as exposure to uncontrollable stress $[109,110]$.

Van Donkelaar et al. $[111,112]$ investigated potential mechanisms by which ATD could exert its effects. It was shown that ATD alters the relation between cerebral blood flow (CBF) and glucose metabolism independent of central 5-HT [112]. Furthermore, Talbot and Cooper [113] investigated the effects of ATD on the regional $\mathrm{CBF}$ in healthy males during rest. After removal of the variance in regional $\mathrm{CBF}$ associated with mood, $\mathrm{ATD}$ reduced the $\mathrm{CBF}$ in the dorsal anterior cingulate cortex, and increased the CBF in the left cuneus, lingual gyrus and the cerebellum. Interestingly, Evers et al. [51] showed that ATD did not affect the task-related BOLD response during a visual checker-board task (control task), suggesting that ATD does not induce vascular effects that lead to a global increase of task-related activation. Two studies [111, 114] showed that brain-derived neurotrophic factor (BDNF) might play a role in the effects of ATD. In contrast, the study of Chair et al. [115] showed that plasma or central BDNF protein levels in the hippocampus and midbrain were not altered by ATD. Furthermore, based on a study of D'Souza et al. [116], Chair et al. [115] speculated that the effects of ATD on the 5-HT2A receptor might be mediated by corticosterone. In addition, Riedel et al [117] showed that ATD blocked the stress-induced cortisol response which is indeed partly 5-HT2A mediated. ATD also blocked the association between cortisol and memory impairment. These findings suggest that ATD-induced alterations go beyond a straightforward dysfunction of the 5-HT system. Also changes seen in depressed patients could be caused by other factors not induced but mediated by 5 -HT levels.

Some findings that were discussed might make us wonder if the effects of ATD are indeed mediated by changes in activity of the 5HT neurons. Firstly, it was shown that ATD modulated the BOLD response in the dorsomedial PFC during negative feedback processing. However, no effects of ATD were found on the feedback related negativity at the $\mathrm{Cz}$. Interestingly, ATD affected cardiac slowing. It might be speculated that changes in cardiac functioning might influence $\mathrm{CBF}$ and thereby change the BOLD response. Secondly, if ATD affects basal 5-HT release, which strongly affects DA release, effects of ATD on DA levels are expected. However, it was repeatedly shown that ATD did not affect DA release.

\subsection{Future Research}

In this section we will give some suggestions for the improvement of future ATD neuroimaging studies. These improvements are necessary to be able to reliably interpret the effects of ATD on brain functioning.

When BOLD fMRI is used to examine the effects of ATD on brain activation, methodological improvements are needed for a better interpretation of changes in BOLD response. Examples of methodological improvements are the inclusion of one or more control tasks, the recording of neuroendocrine (e.g. cortisol and proactive) and physiological parameters (e.g. heart rate, breathing rate) during scanning assessing drug-induced changes in resting state BOLD signal and resting state regional CBF [105]. These methods are at the moment only sparsely applied.
It can be said in addition for all ATD studies that there are too many studies that lack an active comparator condition. This may bias the results and their interpretations considerably. Besides using a control mixture, the recommendation is therefore to always include one other condition in which another amino acid is omitted, but which is not hypothesized to influence the target behavior, or which is hypothesized to influence another behavior.

Since BOLD fMRI is not a good method to measure druginduced changes, other functional brain imaging methods might turn out to be more reliable. Arterial spin labeling [118], which measures CBF, and calibrated fMRI [119], which estimates cerebral metabolic rate of oxygen (CMRO2) are two new and promising methods. Although also indirect measures of neural activity, CBF and $\mathrm{CMRO} 2$ are more directly related to neural activity and less confounded by overall changes in the neurovascular coupling than the BOLD response. We therefore advise future studies to make use of these methods.

More research into the effects of ATD on basal 5-HT release is necessary. Studies are needed that measure the amount of 5-HT efflux in the entire cortex and studies that extend this type of research to animals with a vulnerable 5-HT system will be important [99].

Van Donkelaar et al. [105] suggested that other brain mechanisms might be responsible for the effects of ATD on the BOLD response, and investigated the effects of ATD on BDNF and $\mathrm{CBF}$. Future studies should expand the research into other brain mechanisms that might be modulated by ATD.

\section{CONCLUSIONS}

ATD neuroimaging studies show changes in the BOLD response that resemble the abnormal patterns seen in depressed patients, such as in the PFC and limbic regions. However, at the moment it remains unclear if these changes are related to changes in basal 5-HT release, related to indirect effects of 5-HT on the level of other neurotransmitters, such as ACh and NE, or are related to other biochemical changes that are mediated by ATD.

$\begin{array}{ll}\text { ABBREVIATIONS } \\ \text { 5-HT } & =\text { Serotonin; 5-hydroxytryptamine } \\ \text { 5-HIAA } & =\text { 5-hydroxyindoleaceticacid } \\ \text { 5-HTP } & =\text {-hydroxytryptophan } \\ \text { ACh } & =\text { Acetylcholine } \\ \text { ATD } & =\text { Acute tryptophan depletion } \\ \text { BDNF } & =\text { Brain-derived neurotrophic factor } \\ \text { BOLD } & =\text { Blood Oxygen Level Dependent } \\ \text { CBF } & =\text { Cerebral blood flow } \\ \text { Cz } & =\text { Central position } \\ \text { CMRO2 } & =\text { Cerebral Metabolic Rate of Oxygen } \\ \text { DA } & =\text { Dopamine } \\ \text { EEG } & =\text { Electroencephalogram } \\ \text { ERP } & =\text { Event-related brain potential } \\ \text { FMRI } & =\text { Functional Magnetic Resonance Imaging } \\ \text { LNAA } & =\text { Large Neutral Amino Acids } \\ \text { MEG } & =\text { Magnetoencephalogram } \\ \text { MRI } & =\text { Magnetic Resonance Imaging } \\ \text { NE } & =\text { Norepinephrine } \\ \text { PET } & =\text { Positron Emission Tomography } \\ \text { PFC } & =\text { Prefrontal cortex } \\ \text { Ph-fMRI } & =\text { Pharmacological functional Magnetic } \\ \text { SERT } & =\text { Serotonin transporter }\end{array}$


SSRI $=$ Selective serotonin reuptake inhibitor

TRP $\quad=\quad$ L-tryptophan

\section{REFERENCES}

[1] Feldman RS, Meyer JS, Quenzer LF. Serotonin. In: Feldman RS, Meyer JS, Quenzer LF, Eds. Principles of Neuropsychopharmacology. $1^{\text {st }}$ ed. Sunderland MA: Sinauer 1997; pp. 345-389.

[2] Stahl SM. Stahl's essential psychopharmacology; Neuroscientific basis and practical applications. New York: Cambridge University press 2008; pp. 205-206.

[3] Stahl SM. Stahl's essential psychopharmacology; Neuroscientific basis and practical applications. New York: Cambridge University press 2008; pp. 343-345.

[4] Wurtman RJ, Hefti F, Melamed E. Precursor control of neurotransmitter synthesis. Pharmacol Rev 1980; 32: 315-35.

[5] Biggio G, Fadda F, Fanni P, Tagliamonte A, Gessa GL. Rapid depletion of serum tryptophan, brain tryptophan, serotonin and 5hydroxyindoleacetic acid by a tryptophan-free diet. Life Sci 1974; 14: 1321-9.

[6] Reilly JG, McTavish SF, Young AH. Rapid depletion of plasma tryptophan: a review of studies and experimental methodology. J Psychopharmacol 1997; 11:381-92.

[7] Van der Does AJW. The effects of tryptophan depletion on mood and psychiatric symptoms. J Affect Disord 2001; 64: 107-19.

[8] Fernstrom JD, Faller DV. Neutral amino acids in the brain: changes in response to food ingestion. J Neurochem 1978; 30: 1531-8.

[9] Oldendorf WH, Szabo J. Amino acid assignment to one of three blood-brain-barrier amino acid carriers. Am J Physiol 1976; 230: 94-8.

[10] Blokland A, Lieben C, Deutz NE. Anxiogenic and depressive-like effects, but no cognitive deficits, after repeated moderate tryptophan depletion in the rat. J Psychopharmacol 2002; 16: 3949.

[11] Lieben CK, Blokland A, Westerink B, Deutz NE. Acute tryptophan and serotonin depletion using an optimized tryptophan-free proteincarbohydrate mixture in the adult rat. Neurochem Int 2004; 44: 916.

[12] Nishizawa S, Benkelfat C, Young SN, Leyton M, Mzengeza S, de Montigny $\mathrm{C}$, et al. Differences between males and females in rates of serotonin synthesis in human brain. Proc Natl Acad Sci USA 1997; 94: 5308-13.

[13] Williams WA, Shoaf SE, Hommer D, Rawlings R, Linnoila M. Effects of acute tryptophan depletion on plasma and cerebrospinal fluid tryptophan and 5-hydroxyindoleacetic acid in normal volunteers. J Neurochem 1999; 72: 1641-7.

[14] Young S, Smith SE, Pihl RO, Ervin FR. Tryptophan depletion causes a rapid lowering of mood in normal males. Psychopharmacology (Berl) 1985; 87: 173-7.

[15] Mendelsohn D, Riedel WJ, Sambeth A. Effects of acute tryptophan depletion on memory, attention and executive functions: a systematic review. Neurosci Behav Rev 2009; 33: 926-52.

[16] Mazer C, Muneyyirci J, Taheny K, Raio N, Borella A, WhitakerAzmitia P. Serotonin depletion during synaptogenesis leads to decreased synaptic density and learning deficits in the adult rat: a possible model of neurodevelopmental disorders with cognitive deficits. Brain Res 1997; 760: 68-73.

[17] Barnes J, Costall B, Coughlan J, Domeney AM, Gerrard PA, Kelly ME, et al. The effects of ondansetron, a 5-HT3 receptor antagonist, on cognition in rodents and primates. Pharmacol Biochem Behav 1990; 35: 955-62.

[18] Harrison AA, Everitt BJ, Robbins TW. Central 5-HT depletion enhances impulsive responding without affecting the accuracy of attentional performance: interactions with dopaminergic mechanisms. Psychopharmacology (Berl) 1997; 133: 329-42.

[19] Harrison AA, Everitt BJ, Robbins TW. Central serotonin depletion impairs both the acquisition and performance of a symmetrically reinforced go/no-go conditional visual discrimination. Behav Brain Res 1999; 100: 99-112.

[20] Rogers R, Blackhaw AJ, Middleton HC, Matthews K, Hawtin H, Crowley $\mathrm{C}$, et al. Tryptophan depletion impairs stimulus-reward learning while methylphenidate disrupts attentional control in healthy young adults: implications for the monoaminergic basis of impulsive behaviour. Psychopharmacology 1999; 146: 482-91.

[21] Park SB, Coull JT, McShane RH, Young AH, Sahakian BJ, Robbins TW, et al. Tryptophan depletion in normal volunteers produces selective impairments in learning and memory. Neuropharmacology 1994; 33: 575-88.

Murphy FC, Smith KA, Cowen PJ, Robbins TW, Sahakian BJ. The effects of tryptophan depletion on cognitive and affective processing in healthy volunteers. Psychopharmacology 2002; 163: 42-53.

[23] Rogers R, Tunbridge EM, Bhagwagar Z, Drevets WC, Sahakian BJ, Carter CS. Tryptophan depletion alters decision-making of healthy volunteers through altered processing of reward cues. Neuropsychopharmacology 2003; 28: 153-62.

[24] Sobczak S, Riedel WJ, Booij I, Aan Het Rot M, Deutz NE, Honig A. Cognition following acute tryptophan depletion: difference between first-degree relatives of bipolar disorder patients and matched healthy control volunteers. Psychol Med 2002; 32: 503-15.

[25] Gallagher P, Massey AE, Young AH, McAllister-Williams RH. Effects of acute tryptophan depletion on executive function in healthy male volunteers. BMC Psychiatry 2003; 3: 10.

[26] Booij L, van der Does AJ, Haffmans PM, Riedel WJ, Fekkes D, Blom MJ. The effects of high-dose and low-dose tryptophan depletion on mood and cognitive functions of remitted depressed patients. J Psychopharmacol 2005; 19: 267-7.

[27] Schmitt JA, Jorissen BL, Sobczak S, van Boxtel MP, Hogervorst E, Deutz NE, et al. Tryptophan depletion impairs memory consolidation but improves focused attention in healthy young volunteers. J Psychopharmacol 2000; 14: 21-9.

[28] Scholes KE, Harrison BJ, O’Neill BV, Leung S, Croft RJ, Pipingas $\mathrm{A}$, et al. Acute serotonin and dopamine depletion improves attentional control: findings from the Stroop task. Neuropsychopharmacology 2007; 32: 1600-10.

[29] Cools R, Roberts AC, Robbins TW. Cognitive-emotional interactions: Serotonergic regulation of emotional and behavioural control processes. Trends Cogn Sci 2007; 12: 31-40.

[30] Booij L, Van der Does AJ, Riedel WJ. Monoamine depletion in psychiatric and healthy populations: review. Mol Psychiatry 2003; 8: 951-73.

[31] Harmer CJ, Rogers RD, Tunbridge E, Cowen PJ, Goodwin GM. Tryptophan depletion decreases the recognition of fear in female volunteers. Psychopharmacology (Berl) 2003; 167: 411-7.

[32] Booij L, Van der Does W, Benkelfat C, Bremner JD, Cowen PJ, Fava M, et al. Predictors of mood response to ATD. A reanalysis. Neuropsychopharmacology 2002; 27: 852-61.

[33] Debener S, Strobel A, Kürschner K, Kranczioch C, Hebenstreit J, Maercker A, et al. Is auditory evoked potential augmenting/ reducing affected by acute tryptophan depletion? Biol Psychol 2002; 59: 121-33.

[34] Dierks T, Barta S, Demisch L, Schmeck K, Englert E, Kewitz A, et $a l$. Intensity dependence of auditory evoked potentials (AEPs) as biological marker for cerebral serotonin levels: effects of tryptophan depletion in healthy subjects. Psychopharmacology (Berl) 1999; 146: 101-7.

[35] Kähkönen S, Jääskeläinen IP, Pennanen S, Liesivuori J, Ahveninen J. Acute tryptophan depletion decreases intensity dependence of auditory evoked magnetic N1/P2 dipole source activity. Psychopharmacology (Berl) 2002; 164: 221-7.

[36] Kähkönen S, Ahveninen J, Pennanen S, Liesivuori J, Ilmoniemi RJ, Jääskeläinen IP. Serotonin modulates early cortical auditory processing in healthy subjects: evidence from MEG with acute tryptophan depletion. Neuropsychopharmacology 2002; 27: 862-8.

[37] Kähkönen S, Ahveninen J, Jääskeläinen IP, Pennanen S, Liesivuori $\mathrm{J}$, Nikulin VV. Acute tryptophan depletion does not change somatosensory evoked magnetic fields. Psychopharmacology (Berl) 2003; 170: 332-3.

[38] Knott VJ, Howson AL, Perugini M, Ravindran AV, Young SN. The effect of acute tryptophan depletion and fenfluramine on quantitative EEG and mood in healthy male subjects. Biol Psychiatry 1999; 46: 229-38.

[39] Rubia K, Lee F, Cleare AJ, Tunstall N, Fu CH, Brammer M, et al. Tryptophan depletion reduces right inferior prefrontal activation during response inhibition in fast, event-related fMRI. Psychopharmacology (Berl) 2005; 179: 791-803.

[40] Soubrié P. Reconciling the role of central serotonin neurons in human and animal behaviour. Behav Brain Res 1986; 9: 319-64.

[41] Robbins TW. Chemical neuromodulation of frontal-executive functions in humans and other animals. Exp Brain Res 2000; 133: 130-8.

[42] Evers EA, van der Veen FM, van Deursen JA. Schmitt JA, Deutz NE, Jolles J. Acute tryptophan depletion modulates the BOLD 
response during performance monitoring and response inhibition in healthy male volunteers. Psychopharmacology (Berl) 2006; 187: 200-8.

[43] Clark L, Roiser JP, Cools R, Rubinsztein DC, Sahakian BJ, Robbins TW. Stop signal response inhibition is not modulated by tryptophan depletion or the serotonin transporter polymorphism in healthy volunteers: implications of the 5-HT theory of impulsivity. Psychopharmacology (Berl) 2005; 182: 570-8.

[44] Cools R, Blackwell A, Clark L, Menzies L, Cox S, Robbins TW. Tryptophan depletion disrupts the motivational guidance of goaldirected behavior as a function of trait impulsivity. Neuropsychopharmacology 2005; 30: 1362-73.

[45] LeMarquand DG, Pihl RO, Young SN, Tremblay RE, Seguin JR, Palmour RM, et al. Tryptophan depletion, executive functions, and disinhibition in aggressive, adolescent males. Neuropsychopharmacology 1998; 19: 333-41.

[46] LeMarquand DG, Benkelfat C, Pihl RO, Palmour RM, Young SN. Behavioral disinhibition induced by tryptophan depletion in nonalcoholic young men with multigenerational family histories of paternal alcoholism. Am J Psychiatry 1999; 156: 1771-9.

[47] Crockett MJ, Clark L, Robbins TW. Reconciling the role of serotonin in behavioral inhibition and aversion: acute tryptophan depletion abolishes punishment-induced inhibition in humans. J Neurosci 2009; 29: 11993-9.

[48] Horacek J, Zavesicka L, Tintera J, Dockery C, Platilova V, Kopecek M, et al. The effect of tryptophan depletion on brain activation measured by fMRI during the Stroop test in healthy volunteers. Physiol Res 2005; 54: 235-44.

[49] Evers EA, van der Veen FM, Jolles J, Deutz NE, Schmitt JA. Acute tryptophan depletion improves performance and modulates the BOLD response during a Stroop task in healthy females. NeuroImage 2006; 32: 248-55.

[50] Lamar M, Cutter WJ, Rubia K, Brammer M, Daly EM, Craig MC, et al. 5-HT, prefrontal function and aging: fMRI of inhibition and acute tryptophan depletion. Neurobiol Aging 2009; 30: 1135-46.

[51] Evers EA, Cools R, Clark L, van der Veen FM, Jolles J, Sahakian $\mathrm{BJ}$, et al. Serotonergic modulation of prefrontal cortex during negative feedback in probabilistic reversal learning. Neuropsychopharmacology 2005; 30: 1138-47.

[52] Van der Veen FM, Mies GW, van der Molen MW, Evers EA. Acute tryptophan depletion in healthy males attenuates phasic cardiac slowing but does not affect electro-cortical response to negative feedback. Psychopharmacology (Berl) 2008; 199: 255-63.

[53] Allen PP, Cleare AJ, Lee F, Fusar-Poli P, Tunstall N, Fu CH, et al. Effect of acute tryptophan depletion on pre-frontal engagement. Psychopharmacology (Berl) 2006; 187: 486-97.

[54] McAllister-Williams RH, Massey AE, Rugg MD. Effects of tryptophan depletion on brain potential correlates of episodic memory retrieval. Psychopharmacology (Berl) 2002; 160: 434-42.

[55] Friedman D, Johnson R, Jr. Event-related potential (ERP) studies of memory encoding and retrieval: a selective review. Microsc Res Technol 2000; 51: 6-28.

[56] Van der Veen FM, Evers EA, van Deursen JA, Deutz NE, Backes $\mathrm{WH}$, Schmitt JA. Acute tryptophan depletion reduces activation in the right hippocampus during encoding in an episodic memory task. Neuroimage 2006; 31: 1188-96.

[57] Wang L, Mullette-Gillman O, Gadde KM, Kuhn CM, McCarthy G, Huettel SA. The effect of acute tryptophan depletion on emotional distraction and subsequent memory. Soc Cogn Affect Neurosci 2009; 4(4): 357-68.

[58] Riedel WJ, Klaassen T, Deutz NE, van Someren A, van Praag HM. Tryptophan depletion in normal volunteers produces selective impairment in memory consolidation. Psychopharmacol 1999; 141: 362-9.

[59] Robbins TW, Arnsten AF. The neuropsychopharmacology of frontexecutive function: monoaminergic modulation. Annu Rev Neurosci 2009; 32: 267-87.

[60] Kondo H, Osaka N, Osaka M. Cooperation of the anterior cingulate cortex and dorsolateral prefrontal cortex for attention shifting. Neuroimage 2004; 23: 670-9.

[61] Pollmann S. Anterior prefrontal cortex contributions to attention control. Exp Psychol 2004; 51: 270-8

[62] Hughes JH, Ashton CH, Matthews D, Young AH. Acute depletion of plasma tryptophan does not alter electrophysiological variables in healthy males. Psychopharmacology 2000; 152: 119-21.
[63] Ahveninen J, Kähkönen S, Pennanen S, Liesivuori J, Ilmoniemi RJ, Jäskeläinen IP. Tryptophan depletion effects on EEG and MEG responses suggest serotonergic modulation of auditory involuntary attention in humans. Neuroimage 2002; 16: 1052-61.

[64] Ahveninen J, Jääskeläinen IP, Pennanen S, Liesivuori J, Ilmoniemi RJ, Kähkönen S. Auditory selective attention modulated by tryptophan depletion in humans. Neurosci Lett 2003; 340: 181-4.

[65] Kähkönen S, Mäkinen V, Jääskeläinen IP, Pennanen S, Liesivuori J, Ahveninen J. Serotonergic modulation of mismatch negativity. Psychiatry Res 2005; 138: 61-74.

[66] Näätänen R, Jacobsen T, Winkler I. Memory-based or afferent processes in mismatch negativity (MMN): a review of the evidence. Psychophysiology 2005; 42: 25-32.

[67] Cools R, Calder AJ, Lawrence AD, Clark L, Bullmore E, Robbins TW. Individual differences in threat sensitivity predict serotonergic modulation of amygdala response to fearful faces. Psychopharmacology (Berl) 2005; 180: 670-9.

[68] Carver CS, White TL. Behavioral inhibition, behavioral activation, and affective responses to impending reward and punishment: the BIS/BAS scales. J Pers Soc Psychol 1994; 67: 319- 33.

[69] Van der Veen FM, Evers EA, Deutz NE, Schmitt JA. Effects of acute tryptophan depletion on mood and facial emotion perception related brain activation and performance in healthy females with and without a family history of depression. Neuropsychopharmacology 2007; 32: 216-24

[70] Fusar-Poli P, Allen P, Lee F, Surguladze S, Tunstall N, Fu CH, et al. Modulation of neural response to happy and sad faces by acute tryptophan depletion. Psychopharmacology (Berl) 2007; 193: 3144.

[71] Williams JH, Perrett DI, Waiter GD, Pechey S. Differential effects of tryptophan depletion on emotion processing according to face direction. Soc Cogn Affect Neurosci 2007; 2: 264-73.

[72] Phelps EA, LeDoux JE. Contributions of the amygdala to emotion processing: from animal models to human behavior. Neuron 2005; 48: 175-87.

[73] Munafò MR, Brown SM, Hariri AR. Serotonin transporter (5HTTLPR) genotype and amygdala activation: a meta-analysis. Biol Psychiatry 2008; 63: 852-7.

[74] Drevets WC, Price JL, Bardgett ME, Reich T, Todd RD, Raichle ME. Glucose metabolism in the amygdala in depression: relationship to diagnostic subtype and plasma cortisol levels. Pharmacol Biochem Behav 2002; 71: 431-47.

[75] Sheline YI, Barch DM, Donnelly JM, Ollinger JM, Snyder AZ, Mintun MA. Increased amygdala response to masked emotional faces in depressed subjects resolves with antidepressant treatment: an fMRI study. Biol Psychiatry 2001; 50: 651-8.

[76] Fu CH, Williams SC, Cleare AJ, Brammer MJ, Walsh ND, Kim J. Attenuation of the neural response to sad faces in major depression by antidepressant treatment: a prospective, event-related functional magnetic resonance imaging study. Arch Gen Psychiatry 2004; 61: 877-89.

[77] Del-Ben CM, Deakin JF, McKie S, Delvai NA, Williams SR, Elliott R. The effect of citalopram pretreatment on neuronal responses to neuropsychological tasks in normal volunteers: an FMRI study. Neuropsychopharmacology 2005; 30: 1724-34.

[78] Roiser JP, Levy J, Fromm SJ, Wang H, Hasler G, Sahakian BJ, et $a l$. The effect of acute tryptophan depletion on the neural correlates of emotional processing in healthy volunteers. Neuropsychopharmacology 2008; 33: 1992-2006.

[79] Risch S, Nemeroff CB. Neurochemical alterations of serotonergic neuronal systems in depression. J Clin Psychiatry 1992; 53(Suppl): 3-7.

[80] Benkelfat C, Ellenbogen MA, Dean P, Palmour RM, Young SN. Mood-lowering effect of tryptophan depletion. Enhanced susceptibility in young men at risk for major affective disorder. Arch Gen Psychiatry 1994; 51: 687-97.

[81] Ellenbogen MA, Young SN, Dean P, Palmour RN, Benkelfat C. Mood response to acute tryptophan depletion in healthy volunteers: Sex differences and temporal stability. Neuropsychopharmacology 1996; 15: 465-74.

[82] Klaassen T, Riedel WJ, van Someren A, Deutz NE, Honig A, van Praag HM. Mood effects of 24-hour tryptophan depletion in healthy first-degree relatives of patients with affective disorders. Biol Psychiatry 1999; 15: 489-97.

[83] Neumeister A, Konstantinidis A, Stastny J, Schwarz MJ, Vitouch $\mathrm{O}$, Willeit $\mathrm{M}$, et al. Association between serotonin transporter gene 
promoter polymorphism (5HTTLPR) and behavioural responses to tryptophan depletion in healthy women with and without family history of depression. Arch Gen Psychiatry 2002; 59: 613-20.

[84] Riedel W, Klaassen T, Schmitt JA. Tryptophan, mood, and cognitive function. Brain Behav Immun 2002; 16: 581-9.

[85] Riedel W, Sobczak S, Schmitt JA. Tryptophan modulation and cognition. Adv Exp Med Biol 2003; 527: 207-13

[86] Drevets WC, Price JL, Furey ML. Brain structural and functional abnormalities in mood disorders: implications for neurocircuitry models of depression. Brain Struct Funct 2008; 213: 93-118. Review.

[87] Sakai Y, Nishikawa M, Leyton M, Benkelfat C, Young SN, Diksic M. Cortical trapping of alpha-[(11)C]methyl-1-tryptophan, an index of serotonin synthesis, is lower in females than males. Neuroimage 2006; 33: 815-24.

[88] Blakely RD, Ramamoorthy S, Schroeter S, Qian Y, Apparsundaram $\mathrm{S}$, Galli $\mathrm{A}$, et al. Regulated phosphorylation and trafficking of antidepressant-sensitive serotonin transporter proteins. Biol Psychiatry 1998; 44: 169-78. Review.

[89] Zahniser NR, Doolen S. Chronic and acute regulation of $\mathrm{Na}+\mathrm{Cl}-$ dependent neurotransmitter transporters: drugs, substrates, presynaptic receptors, and signaling systems. Pharmacol Ther 2001; 92: 21-55. Review.

[90] Talbot P, Frankle WG, Hwang D-R, Huang Y, Suckow RF, Slifstein M, et al. Effects of reduced endogenous 5-HT on in vivo binding of the serotonin transporter radioligand 11C-DASB in healthy humans. Synapse 2005; 55: 164-75.

[91] Praschak-Rieder N, Wilson AA, Hussey D, Carella A, Wei C, Ginovart $\mathrm{N}$, et al. Effects of tryptophan depletion on the serotonin transporter in healthy humans. Biol Psychiatry 2005; 558: 825-30.

[92] Udo de Haes JI, Bosker FJ, Van Waarde A, Pruim J, Willemsen AT, Vaalburg W, et al. 5-HT1A receptor imaging in the human brain: effects of tryptophan depletion and infusion on [18F]MPPF binding. Synapse 2002; 46: 108-15.

[93] Rabiner EA, Sargent PA, Opacka-Juffry J, Gunn RN, Bench CJ, Cowen PJ, et al. Is [11C]WAY-100635 sensitive to changes in brain 5-HT? Neuroimage 2000; 11: S9.

[94] Yatham L, Liddle PF, Shiah IS, Lam RW, Adam MJ, Zis AP, et al. Effects of rapid tryptophan depletion on brain 5-HT2 receptors: a PET study. Br J Psychiatry 2001; 178: 448-53.

[95] Cahir M, Ardis T, Reynolds GP, Cooper SJ. Acute and chronic tryptophan depletion differentially regulate central 5-HT1A and 5HT2A receptor binding in the rat. Psychopharmacology (Berl) 2007; 190: 497-506.

[96] Briand LA, Gritton H, Howe WM, Young DA, Sarter M. Modulators in concert for cognition: modulator interactions in the prefrontal cortex. Prog Neurobiol 2007; 83: 69-9.

[97] Robbins TW. Arousal systems and attentional processes. Biol Psychol 1997; 45: 57-71.

[98] Young S, Ervin FR, Pihl RO, Finn P. Biochemical aspects of tryptophan depletion in primates. Psychopharmacology (Berl) 1989; 98: 508-11.

[99] Ardis TC, Cahir M, Elliott JJ, Bell R, Reynolds GP, Cooper SJ. Effect of acute tryptophan depletion on noradrenaline and dopamine in the rat brain. J Psychopharmacol 2009; 23: 51-5.

[100] Van der Plasse G, Meerkerk DT, Lieben CK, Blokland A, Feenstra MG. Lack of evidence for reduced prefrontal cortical serotonin and dopamine efflux after acute tryptophan depletion. Psychopharmacology (Berl) 2007; 195: 377-85.

[101] Lieben CK, Blokland A, Sik A, Sung E, van Nieuwenhuizen P, Schreiber R. The selective 5-HT6 receptor antagonist Ro4368554 restores memory performance in cholinergic and serotonergic models of memory deficiency in the rat. Neuropsychopharmacology 2005; 30: 2169-79.

[102] Roiser JP, Blackwell AD, Cools R, Clark L, Rubinsztein DC, Robbins TW, et al. Serotonin transporter polymorphism mediates vulnerability to loss of incentive motivation following acute tryptophan depletion. Neuropsychopharmacology 2006; 31: 226472

[103] Roiser JP, de Martino B, Tan GC, Kumaran D, Seymour B, Wood $\mathrm{NW}$, et al. A genetically mediated bias in decision making driven by failure of amygdala control. J Neurosci 2009; 29: 5985-91

[104] Sambeth A, Blokland A, Harmer CJ, Kilkens TO, Nathan PJ, Porter $\mathrm{RJ}$, et al. Sex differences in the effect of acute tryptophan depletion on declarative episodic memory: a pooled analysis of nine studies. Neurosci Biobehav Rev 2007; 31: 516-29.

[105] Ianetti GD, Wise RG. BOLD response functional MRI in disease and pharmacological studies: Room for improvement? Magn Reson Imaging 2007; 25: 978-88.

[106] Van Donkelaar EL. Challenging the serotonin system; a mechanistic approach to the method of acute tryptophan depletion in rodents. $\mathrm{PhD}$ thesis. Maastricht 2009.

[107] Moreno FA, Parkinson D, Palmer C, Castro WL, Misiaszek J, El Khoury A, et al. CSF neurochemicals during tryptophan depletion in individuals with remitted depression and healthy controls. Eur Neuropsychopharmacology 2010; 20(1): 18-24.

[108] Trulson ME. Dietary tryptophan does not alter the function of brain serotonin neurons. Life Sci 1985; 37: 1067-72.

[109] De Kloet ER, Kovács GL, Szabó G, Telegdy G, Bohus B, Versteeg DH. Decreased serotonin turnover in the dorsal hippocampus of rat brain shortly after adrenalectomy: selective normalization after corticosterone substitution. Brain Res 1982; 239: 659-63.

[110] De Kloet ER, Versteeg DH, Kovacs GL. Aldosterone blocks the response to corticosterone in the raphe-hippocampal serotonin system. Brain Res 1983; 264: 323-7.

[111] Van Donkelaar EL, van den Hove DL, Blokland A, Steinbusch HW, Prickaerts J. Stress-mediated decreases in brain-derived neurotrophic factor as potential confounding factor for acute tryptophan depletion-induced neurochemical effects. Eur Neuropsychopharmacol 2009; 19: 812-21.

[112] Van Donkelaar EL, Ferrington L, Blokland A, Steinbusch HW, Prickaerts J, Kelly PA. Acute tryptophan depletion in rats alters the relationship between cerebral blood flow and glucose metabolism independent of central serotonin. Neuroscience 2009b; 163: 68394.

[113] Talbot PS, Cooper SJ. Anterior cingulate and subgenual prefrontal blood flow changes following tryptophan depletion in healthy males. Neuropsychopharmacology 2006; 31: 1757-67.

[114] Neumeister A, Yuan P, Young TA, Bonne O, Luckenbaugh DA Charney DS, et al. Effects of tryptophan depletion on serum levels of brain-derived neurotrophic factor in unmedicated patients with remitted depression and healthy subjects. Am J Psychiatry 2005; 162: 805-7.

[115] Cahir M, Ardis TC, Elliott JJ, Kelly CB, Reynolds GP, Cooper SJ. Acute tryptophan depletion does not alter central or plasma brainderived neurotrophic factor in the rat. Eur Neuropsychopharmacol 2008; $18: 317-22$.

[116] D'Souza DN, Zhang Y, Garcia F, Battaglia G, Van de Kar LD. Fluoxetine-induced changes in body weight and 5-HT1A receptormediated hormone secretion in rats on a tryptophan-deficient diet. Am J Physiol Regul Integr Comp Physiol 2004; 286: R390-7.

[117] Riedel WJ, Sobczak S, Nicolson N, Honig A. Stress, cortisol and memory as markers of serotonergic vulnerability. Acta Neuropsychiatrica 2002b; 14: 186-91.

[118] Paiva FF, Tannús A, Silva AC. Measurement of cerebral perfusion territories using arterial spin labelling. NMR Biomed 2007; 20: 633-42. Review.

[119] Davis TL, Kwong KK, Weisskoff RM, Rosen BR. Calibrated functional MRI: mapping the dynamics of oxidative metabolism. Proc Natl Acad Sci USA 1998; 95 : 1834-9. 